\title{
Analysis of Blotter Papers Employed in the Commercialization of New Hallucinogenic Substances of the 2,5-Dimethoxy- $N$-(2-methoxybenzyl) Phenethylamine Series Seized in the City of Bogotá by Applying Gas Chromatography Coupled to a Selective Mass Ion Trap Detector
}

\author{
Diego A. Sánchez Robayo, ${ }^{a, b}$ William F. Garzón Mendez, ${ }^{b}$ Gonzalo Taborda Ocampo ${ }^{a}$ and \\ Milton Rosero Moreano ${ }^{*, a}$ \\ ${ }^{a}$ Department of Chemistry, Faculty of Natural and Exact Sciences, Universidad de Caldas, \\ Calle 65 No. 26-10, Manizales, Colombia \\ ${ }^{b}$ Chemistry Group, Central-Level, Attorney General of Colombia, Diagonal 22B No. 52-01, \\ Building L, $3^{\text {rd }}$ floor, Bogotá, Colombia
}

\begin{abstract}
In recent years, the production, distribution and consumption of so-called new psychoactive substances, such as synthetic cannabinoids, synthetic cathinones, and phenethylamines, have increased worldwide. The present work reports the identification of such substances found in samples of blotter papers that were seized in the city of Bogotá in accordance with the analytical method implemented in the chemistry laboratories of the Attorney General of Colombia. Using gas chromatography coupled to a selective mass ion trap detector, the presence of phenethylamine derivatives, mainly from the 2,5-dimethoxy- $N$-(2-methoxybenzyl) phenethylamine series, was detected. Among them, 2-(4-chloro-2,5-dimethoxy- $N$-(2-methoxybenzyl)) phenethylamine, 2-(4-bromo-2,5-dimethoxy- $N$-(2-methoxybenzyl)) phenethylamine, and 2-(4-iodo-2,5-dimethoxy$N$-(2-methoxybenzyl)) phenethylamine $(\mathrm{m} / \mathrm{z}, 150,121,91)$ were prevalent. The 2,5 -dimethoxy- $N$ (2-methoxybenzyl) phenethylamine series derivatives correspond to proved powerful hallucinogens that have not yet been subjected to international control and supervision.
\end{abstract}

Keywords: synthetic drugs, blotter papers, phenethylamines, NBOMe series, GC-MS IT

\section{Introduction}

Since the year 2012, the forensic chemistry laboratory of the Attorney General of Colombia has noted an increase in the quantity of blotter paper samples received for substance analysis as part of judicial investigations for the crimes of trafficking, possession, or distribution of drugs according to the Colombian Penal Code. Moreover, the gas chromatography coupled to a selective mass detector (GC-MS) analyses show no lysergic acid diethylamide (LSD) content, as has been traditionally found.

The blotter papers with logos and bright colors are used as suppport for the distribution of synthetic drugs whose effects are achieved in the microgram level; recent results have shown that blotter papers ${ }^{1,2}$ are used for impregnation and subsequent marketing of new hallucinogenic drugs or a mixture of drugs derived from the tryptamine and

*e-mail: milton.rosero@ucaldas.edu.co phenethylamine families. ${ }^{3}$ In the latter drug family, it is common to find previously described derivatives from the 2,5-dimethoxy-phenethylamine (2C series), ${ }^{4,5}$ which are known as the 2,5-dimethoxy- $N$-(2-methoxybenzyl) phenethylamine (NBOMe) family; this last group of novel synthetic hallucinogens ${ }^{6}$ is synthesized by substituting the nitrogen $(\mathrm{N})$ of the $2 \mathrm{C}$ series with a 2-methoxybenzyl (BOMe) group. ${ }^{1}$

Figure 1 shows the structural relationship between the $2 \mathrm{C}$ series and its derivative NBOMe.

Substitutions in the $2 \mathrm{C}$ structure, such as the addition of methoxy groups in carbons 2 and 5 of the benzene ring or a halogen substitution in the $\mathrm{R} 1$ position, increase the hallucinogenic effect of the substance., ${ }^{4,5}$

25R1-NBOMe is the short name for 4-R1-2,5dimethoxyphenyl- $N$-[(2-methoxyphenyl)methyl] ethanamine, where R1 can refer to a hydrogen $(\mathrm{H})$, ethyl group (E), chlorine (C), bromine (B), or iodine (I), among others (Figure 1c). 
(a)<smiles></smiles><smiles>[R]NCc1ccccc1OC</smiles><smiles>[R7]S1=C(OC)[PH](CCNCc2ccccc2OC)=[SH](OC)=C1OC</smiles>

Figure 1. General chemical structure of the $2 \mathrm{C}$ series (a); NBOMe (b) and 25R1-NBOMe (c)

The high hallucinogenic potential of NBOMe series derivatives lies in the fact that they are powerful agonists of serotonin receptors; these receptors are implicated in the pathophysiology of depression, schizophrenia and hallucinogenic activity. ${ }^{6}$

Few scientific studies have shown the toxicological effects caused by the ingestion of NBOMe series substances. ${ }^{6-8}$ Research has been primarily focused on human post mortem detection ${ }^{9,10}$ and in some cases, in the field of clinical pharmacology; ${ }^{11-13}$ in Colombia, the only study that has been reported was performed in 2010 and focused on the analysis of substances commercialized in the city of Bogotá under the name synthetic drugs. ${ }^{14}$

Colombian law, unlike that of other countries, ${ }^{15}$ does not regulate the production and distribution of derivatives of the NBOMe series because these derivatives are not officially included in the lists for control and supervision of psychotropic substances provided by the United Nations. This situation favors the continuous production and distribution of new psychoactive substances by criminals. Moreover, recent research shows that these substances can be used as adulterants of traditional drugs. ${ }^{3-15}$

The aim of the present study is to propose a method for the qualitative analysis of substances of the NBOMe series found in blotter papers using gas chromatography coupled to a selective mass ion trap detector (GC-MS IT). This analytical method was tested using samples collected in the city of Bogotá with the aim of providing evidence regarding the marketing of new psychoactive substances.

\section{Experimental}

Reagents

Methanol high-performance liquid chromatography (HPLC) grade was purchased from Scientific Products
(Bogotá, Colombia). Tetracosane with purity of $99 \%$ was acquired from Sigma-Aldrich (St. Louis, MO, USA) and was employed as internal standard. A C8-C40 alkanes calibration standard (98\%) was acquired from Casa Cientifica (Bogotá, Colombia). Certified analytical standards of 25H-NBOMe, 25E-NBOMe, 25C-NBOMe, 25B-NBOMe, and 25I-NBOMe with purity between 99.4 and $99.9 \%$ were purchased from Química M. G. S. A. S. (Bogotá, Colombia) and certified analytical standards of other types of drugs were acquired from Lipomed through Química M. G. S. A. S. Samples of blotter papers linked to crimes related to the manufacturing, trafficking and sale of drugs $(n=48)$ were collected in the city of Bogotá and transported to the chemistry laboratory of the Attorney General of Colombia (Figure 2).

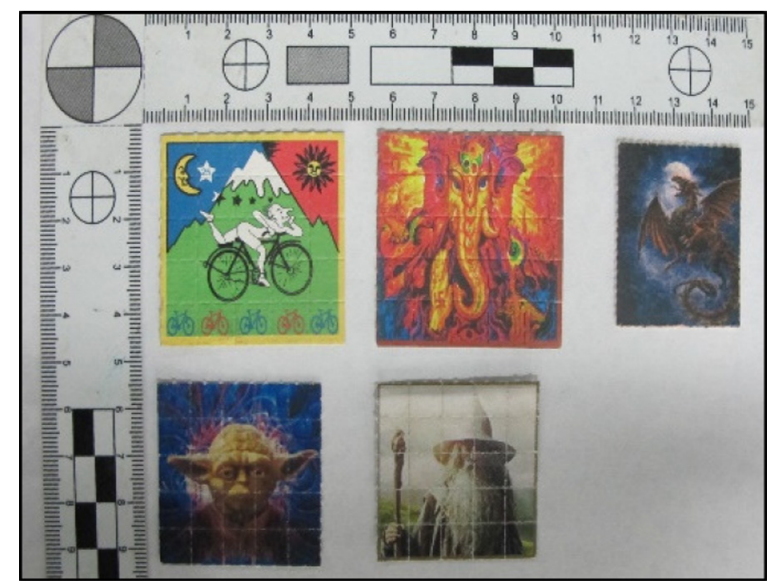

Figure 2. Blotter paper samples impregnated with drugs.

\section{GC-MS IT}

The analysis using GC-MS IT was performed on an Agilent 7890A-240MS instrument (Santa Clara, CA, USA). ${ }^{16}$ The extracts were automatically injected in a split 20:1 mode. An Agilent VF-5MS capillary column (30 $\mathrm{m} \times 250 \mu \mathrm{m} \times 0.25 \mu \mathrm{m},(5 \%$-phenyl)-methylpolysiloxane) was used for chromatographic separation. Helium (grade 5.0, purity $99.999 \%, 1 \mathrm{~mL} \mathrm{~min}^{-1}$ ) was used as the carrier gas. The column temperature was initially maintained at $100{ }^{\circ} \mathrm{C}$ for $30 \mathrm{~s}$ and then increased to $280{ }^{\circ} \mathrm{C}$ at a rate of $12{ }^{\circ} \mathrm{C} \mathrm{min}^{-1}$ for a total run time of $20.5 \mathrm{~min}$. The mass spectrometer operated in an electron impact mode $(70 \mathrm{eV})$, and the ion-source temperature was $250{ }^{\circ} \mathrm{C}$. Fragment acquisition was achieved in the scan mode in a scan range of 29 to $450 \mathrm{Da}$ (see characteristic fragments in Table 1) with an injection volume of $1.0 \mu \mathrm{L}$. The identification of the analytes found in the blotter paper samples was accomplished by comparing the retention times and the characteristics of the analytes with those of the reference standards used. 
Table 1. Chromatographic parameters for the analytes of interest

\begin{tabular}{|c|c|c|c|c|c|c|c|c|}
\hline Substance $^{\mathrm{a}}$ & $\begin{array}{l}\text { Retention } \\
\text { time / min }\end{array}$ & Peak width (W) & Resolution (R) & $\begin{array}{l}\text { Relative } \\
\text { retention }(\alpha)\end{array}$ & $\begin{array}{l}\text { Retention } \\
\text { (capacity) } \\
\text { factor }\left(\mathrm{K}^{\prime}\right)\end{array}$ & $\begin{array}{l}\text { Theoretical plate } \\
\text { (efficiency) (N) }\end{array}$ & Kovats index & $\begin{array}{l}\text { Characteristic } \\
\text { fragment }(\mathrm{m} / \mathrm{z})\end{array}$ \\
\hline 25H-NBOMe & $14.340 \pm 0.003$ & 0.084 & 4.88 & 12.57 & 1.03 & 471908 & 2459 & $\begin{array}{c}91,121,150 \\
165,270\end{array}$ \\
\hline 25E-NBOMe & $14.923 \pm 0.006$ & 0.105 & 6.19 & 13.12 & 1.04 & 324439 & 2548 & $\begin{array}{c}91,121,150 \\
180,296\end{array}$ \\
\hline 25C-NBOMe & $15.425 \pm 0.009$ & 0.095 & 2.17 & 13.60 & 1.01 & 426292 & 2626 & $\begin{array}{c}91,121,150 \\
185,302\end{array}$ \\
\hline 25B-NBOMe & $16.068 \pm 0.009$ & 0.095 & 6.81 & 14.21 & 1.05 & 462584 & 2723 & $\begin{array}{c}91,121,150 \\
230,348\end{array}$ \\
\hline 25I-NBOMe & $16.941 \pm 0.012$ & 0.080 & 10.02 & 15.03 & 1.06 & 724706 & 2838 & $\begin{array}{c}91,121,150 \\
247,278\end{array}$ \\
\hline
\end{tabular}

a4-R1-2,5-Dimethoxyphenyl- $N$-[(2-methoxyphenyl)methyl]ethanamine, where R1 refers to a hydrogen (H), ethyl group (E), chlorine (C), bromine (B), or iodine (I).

\section{Extraction procedure}

Whole blotter paper (dose) of dimensions $0.7 \times 0.7 \mathrm{~cm}$ was transferred into sample glass vial $(1.5 \mathrm{~mL}), 100 \mu \mathrm{L}$ of internal standard $\left(1000 \mathrm{mg} \mathrm{L}^{-1}\right)$ and $900 \mu \mathrm{L}$ of methanol were added, and the vial was sonicated for $10 \mathrm{~min}$. The extracts were analyzed directly by GC-MS IT.

\section{Results and Discussion}

By following a standard method applied by the United Nations Office on Drugs and Crime (UNODC) ${ }^{17}$ for the qualitative detection of substances impregnated in blotter papers some important analytical characteristics were verified. The detection limits for $25 \mathrm{H}-\mathrm{NBOMe}$, 25E-NBOMe, 25C-NBOMe, 25B-NBOMe, and 25I-NBOMe were experimentally determined using serial dilutions. The resulting values were 9.1, 10.1, 9.1, 10.7, and $9.5 \mathrm{mg} \mathrm{L}^{-1}$, respectively. Chromatography parameters and
Kovats retention indices were also determined (Table 1). An excellent chromatographic resolution was obtained for the analyzed components (higher than 1.5). The analytes of interest were eluted at retention times greater than $14 \mathrm{~min}$; separation of a large number of commonly abused drugs is achieved in less time. The Kovats retention indices for the compounds of interest were calculated according to the chromatographic conditions, and analogous results to the retention time of an alkane that contains between 24 and 28 carbon atoms were obtained.

The signal of the compounds of the NBOMe series does not coelute with signals from other drugs of synthetic type and the mass spectra are different for each compound according to the abundances of the characteristic fragments; the analysis method is selective and specific for the analytes of interest (Table 1 and Figure 3).

The developed method has shown good performance in terms of reproducibility and repeatability because no statistical differences were found in the retention times

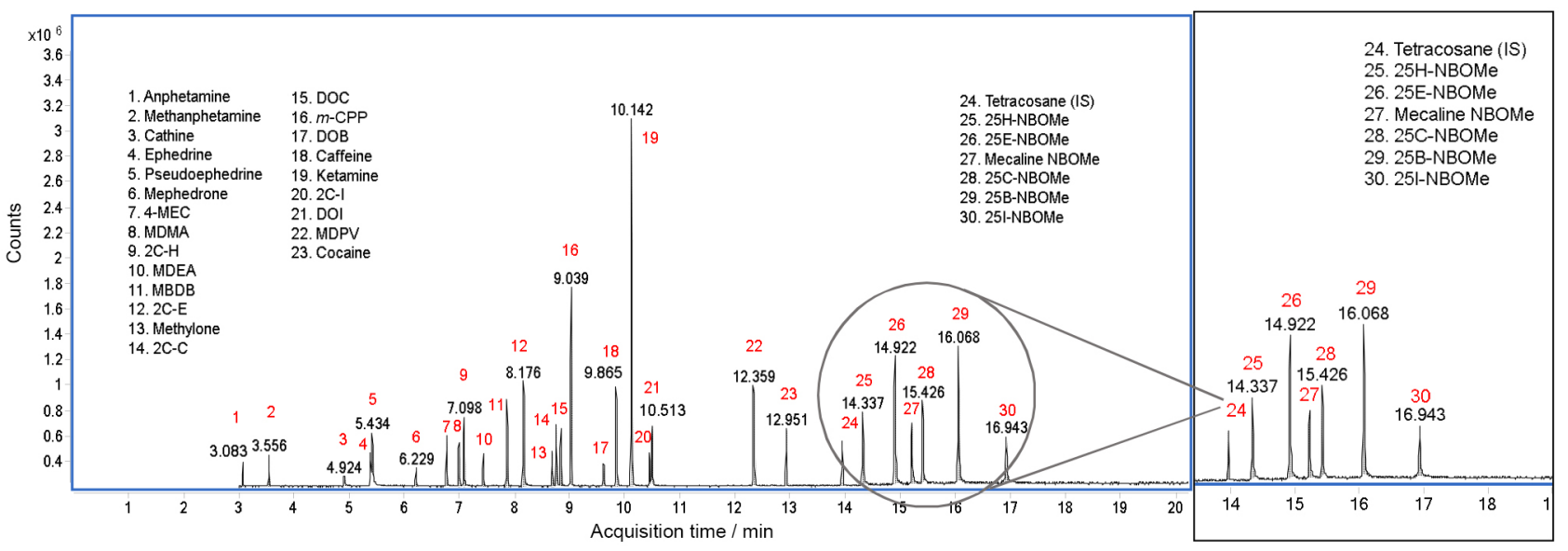

Figure 3. Chromatogram of a mixture of standards at $200 \mathrm{mg} \mathrm{L}^{-1}$ of different abused drugs. 
Table 2. Average retention time and fragment characteristics of the substances found in the blotter paper samples

\begin{tabular}{lccc}
\hline Substance & Molecular weight $/\left(\mathrm{g} \mathrm{mol}^{-1}\right)$ & Retention time $/ \mathrm{min}$ & Characteristic fragment $(\mathrm{m} / \mathrm{z})$ \\
\hline $25 \mathrm{E}-\mathrm{NBOMe}$ & 329.44 & 14.918 & $91,121,150,180,296$ \\
$25 \mathrm{C}-\mathrm{NBOMe}^{\mathrm{a}}$ & 335.83 & 15.421 & $91,121,150,185,302$ \\
$25 \mathrm{~B}-\mathrm{NBOMe}^{\mathrm{a}}$ & 380.28 & 16.065 & $91,121,150,230,348$ \\
$25 \mathrm{I}-\mathrm{NBOMe}^{\mathrm{a}}$ & 427.28 & 16.936 & $91,121,150,247,278$ \\
Escaline & 225.14 & 8.881 & $123,167,196,225$ \\
DOC & 229.08 & 8.850 & $44,125,171,186$ \\
DOI & 321.02 & 10.502 & $44,145,247,278$ \\
\hline
\end{tabular}

a4-R1-2,5-Dimethoxyphenyl- $N$-[(2-methoxyphenyl)methyl]ethanamine, where R1 refers to an ethyl group (E), chlorine (C), bromine (B), or iodine (I). DOC: 2,5-dimethoxy-4-chloroamphetamine; DOI: 2,5-dimethoxy-4-iodoamphetamine.

and mass spectra between the certified analytical standards of the NBOMe and the real samples with respect to the target analytes.

The GC-MS IT analysis of the 48 blotter paper samples led to the detection of 25E-NBOMe, 25C-NBOMe, 25B-NBOMe, and 25I-NBOMe. Moreover, impregnated amphetamine derivatives of the 4-X-2,5dimethoxyamphetamine (DOX) series were found, which correspond to synthetic drugs developed during the $1980 \mathrm{~s}^{4}{ }^{4}$ the presence of escaline (4-ethoxy-mescaline) was also detected in two samples. The identification was performed according to the retention time of each analyte and its respective mass fragmentation based on the literature and forensic libraries. ${ }^{2-18}$ Table 2 shows the fragment characteristics of the substances found in the blotter paper samples.

Interestingly, a mixture of several of these substances was found in five samples. In other words, in a single blotter paper sample, more than one abused drug was found. Figure 4 shows the results for one of these samples.

The comparison between a real sample and a standard is shown in Figure 5 (chromatograms) and Figure 6 (mass spectra with the result of different samples).

Figure 7 shows the results of the analyzed samples. It

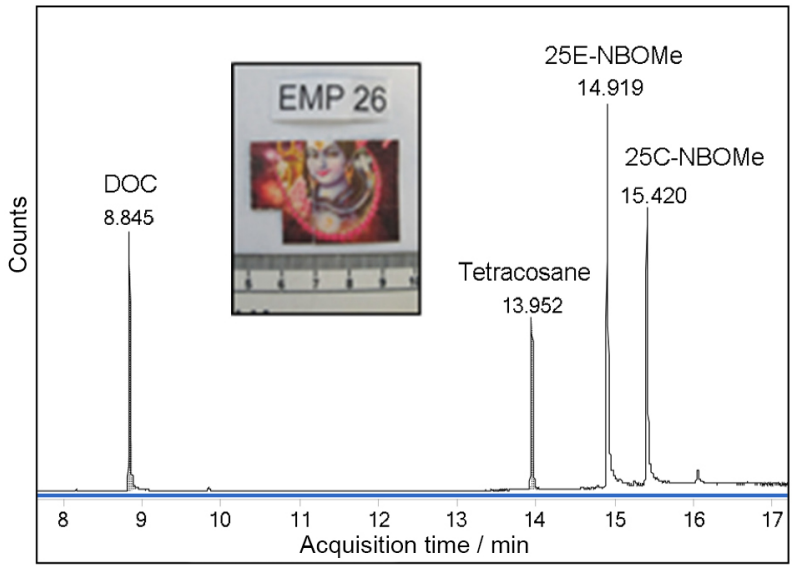

Figure 4. Chromatogram of sample 26.

is noteworthy that four samples contain two analytes, and one sample contains three impregnated substances.

\section{Conclusions}

The developed method enables the identification of the NBOMe series and other drugs in blotter paper samples, which is used as part of the evidence for the solution of different crime cases related with traffic and consumption

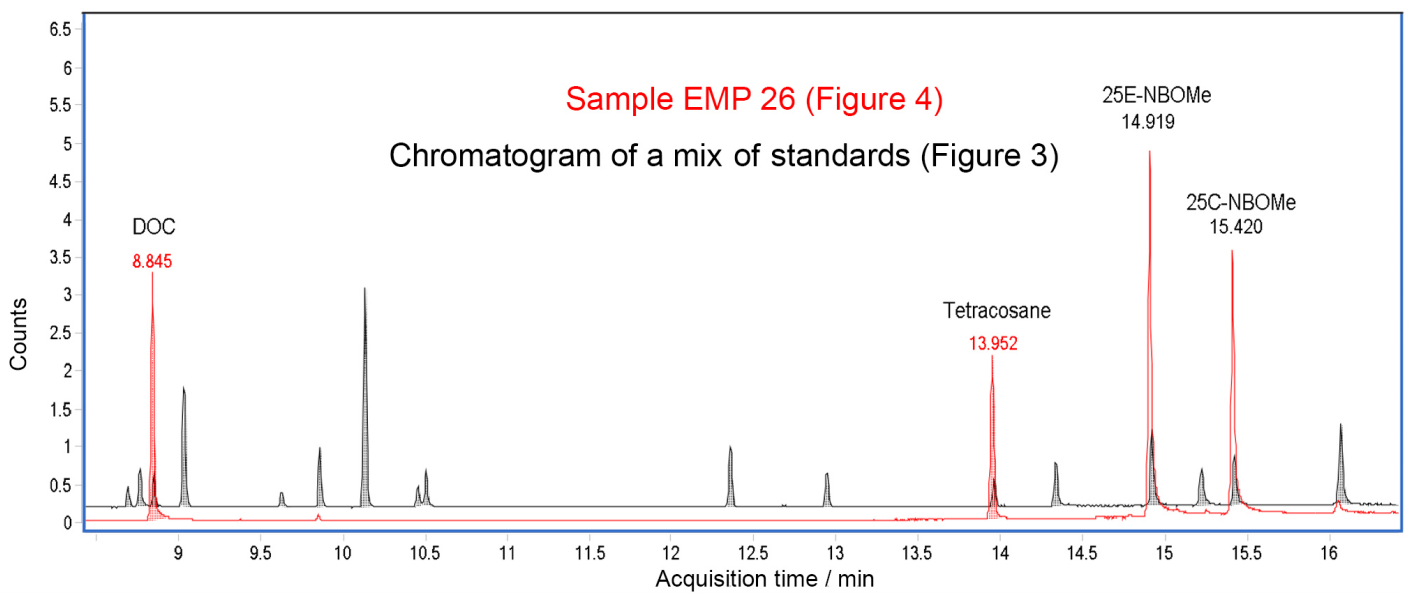

Figure 5. Overlapping chromatograms of mixture of standards at $200 \mathrm{mg} \mathrm{L}^{-1}$ and real sample 26. 

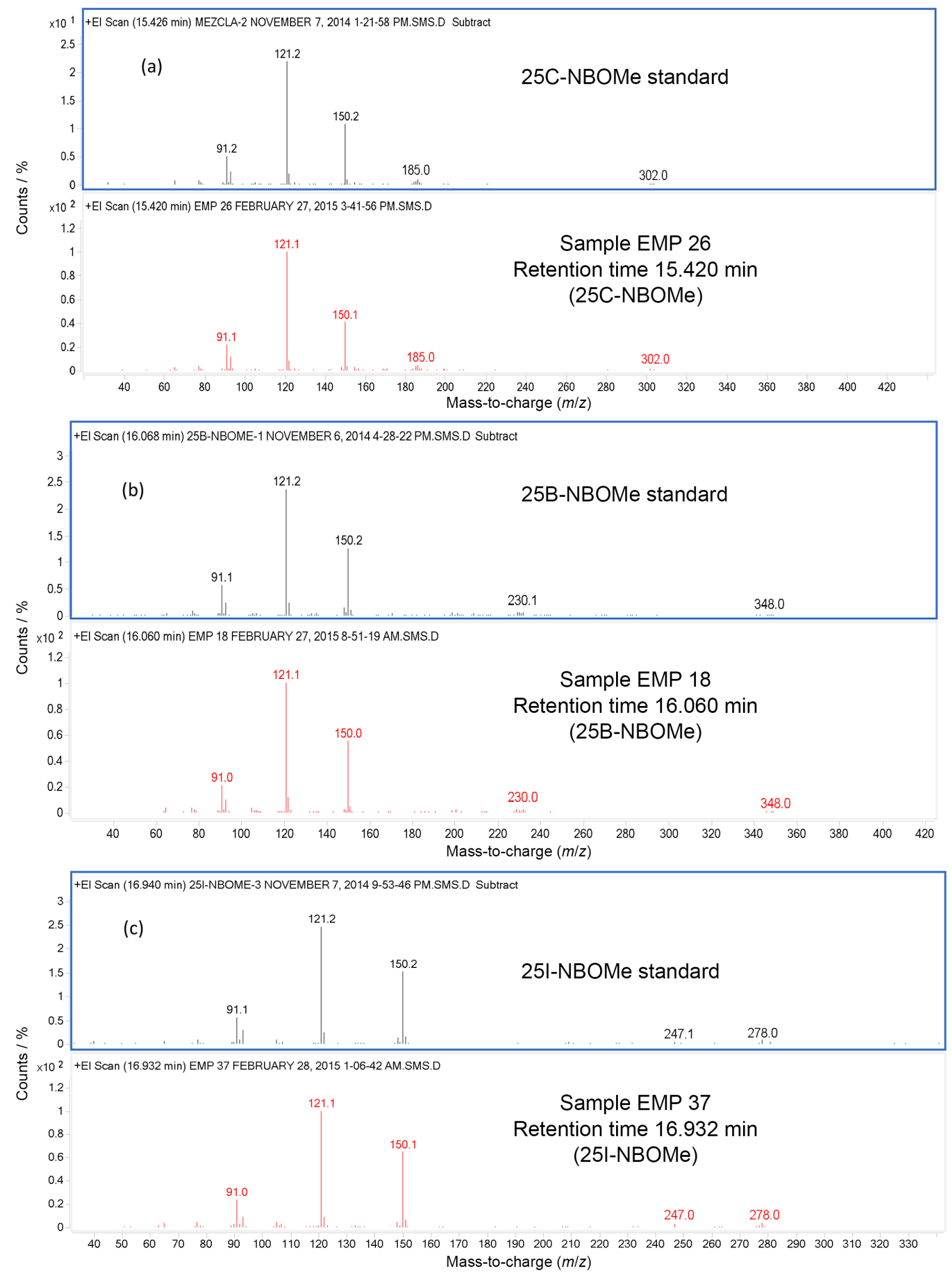

Figure 6. Comparison of mass spectra of (a) 25C-NBOMe standard and sample EMP 26; (b) 25B-NBOMe standard and sample EMP 18 and (c) 25I-NBOMe standard and sample EMP 37. 


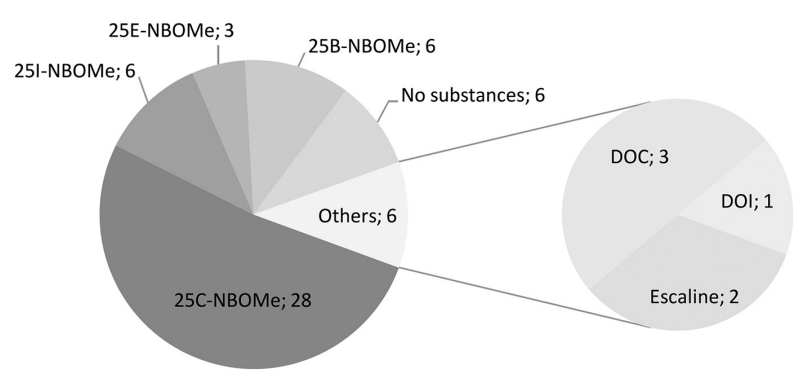

Figure 7. Number of blotter paper samples containing abused drugs.

of new emergent abused drugs in Bogotá's streets by the Attorney General of Colombia.

Different abused drugs, mainly phenethylamine derivatives of the NBOMe series and amphetamine derivatives of the DOX series, were found in the samples of blotter papers; all of these substances have a proved hallucinogenic potential. $25 \mathrm{C}-\mathrm{NBOMe}$ was the predominant substance in more than half of the samples studied. One substance found in two samples was escaline, which corresponds to a hallucinogenic derivative of mescaline that is more powerful than mescaline; ${ }^{4}$ it is a less common drug, which may indicate a new alternate market of emerging hallucinogens.

These results show that in the city of Bogotá, blotter papers commonly used for LSD marketing contain other types of substances that belong mainly to the NBOMe series and present effects similar to LSD. This situation alarms different authorities, considering the toxicological effects that could be produced by the consumption of novel drugs or a mixture of these drugs, as shown in the present work.

This is the first work performed in Colombia that shows the evolution of new drugs of abuse and the first work in Bogotá showing the commercialization of escaline as an impregnated drug in blotter paper.

\section{References}

1. Zuba, D.; Sekula, K.; Forensic Sci. Int. 2013, 227, 7.

2. Casale, J.; Hays, P.; Microgram J. 2012, $9,84$.

3. Giné, C. V.; Espinosa, I. F.; Vilamala, M. V.; Drug Test. Anal. 2014, 6, 819 .

4. Shulgin, A.; Shulgin, A.; Phenethylamines I Have Known and Loved: A Chemical Love Story; Transform Press: Berkeley, 2002.

5. Dean, B. V.; Stellpflug, S.; J. Med. Toxicol. 2013, 9, 172.

6. Ettrup, A.; Hansen, M.; Santini, M. A.; Paine, J.; Gillings, N.; Palner, M.; Knudsen, G. M.; Eur. J. Nucl. Med. Mol. Imaging 2011, 38, 681 .

7. Suzuki, J.; Dekker, M. A.; Valenti, E. S.; Cruz, F. A. A.; Correa, A. M.; Poklis, J. L.; Poklis, A.; Psychosomatics 2015, $56,129$.

8. Halberstadt, A.; Geyer, M.; Neuropharmacology 2014, 77, 200.

9. Poklis, J. L.; Devers, K. G.; Arbefeville, E. F.; Pearson, J. M.; Houston, E.; Poklis, A.; Forensic Sci. Int. 2014, 234, 14.

10. Armenian, P.; Gerona, R. R.; Am. J. Emerg. Med. 2014, 11, 3.

11. Rose, S. R.; Poklis, J. L.; Poklis, A.; Clin. Toxicol. 2013, 51, 174.

12. Poklis, J. L.; Charles, J.; Wolf, C. E.; Poklis, A.; Biomed. Chromatogr. 2013, 27, 1794.

13. Stellpflug, S. J.; Kealey, S. E.; Hegarty, C. B.; Janis, G. C.; J. Med. Toxicol. 2014, 10, 45.

14. Contreras, H. H. B.; Revista de la Integración 2010, 6, 105.

15. https://www.unodc.org/LSS/Page/NPS/LegalResponses accessed in December 2015.

16. http://www.unodc.org/pdf/scientific/stnar34.pdf accessed in December 2015.

17. http://www.unodc.org/documents/scientific/validation_E.pdf accessed in December 2015.

18. http://forendex.southernforensic.org/ accessed in December 2015. 